\title{
THE TRIP OF ASSOCIATE SECRETARY \\ M. H. INGRAHAM IN THE INTERESTS OF THE SOCIETY
}

The editors of this Bulletin have invited me to make a statement about the work I am to do during the academic year 1934-1935 in helping to put into operation the proposals for stabilizing the Society's finances. I greatly appreciate this kindness.

President Coble in his letter of May 19th to the members of the American Mathematical Society discussed the financial needs of the Society and the program which the trustees and council had adopted to meet the present emergency. He also outlined the plan which involves my visiting various American colleges and universities in order to advance the interests of the Society. It is hoped that my efforts will be helpful in initiating the plan of individual contributing membership and in securing cooperation of institutions of learning in our program for maintaining channels of mathematical publication.

Since Professor Coble wrote, a careful study of the distribution of papers in our mathematical research periodicals by universities and colleges during the last seven years has been completed, and the annual amount which a university would have to pay as a sustaining member if it were to contribute to the Society $\$ 2.75$ per page of publication by its faculty members has been computed. It is of course realized that this will merely serve as a rough guide for universities and colleges in determining the size of the contributions they may wish to make. Besides this, much information has been gathered concerning the publication problems in other sciences so that university authorities can be better informed as to the whole situation which it is likely they must ultimately face. In some cases the financial conditions of learned societies are such that there is little probability that any aid will be asked from the universities. In others, such as physics and biology, universities are already helping by paying part of the publication cost for the papers of their faculty members. It is expected that by presenting as much information as possible to the mathematical groups, the members of the Society will themselves come to a clearer un- 
derstanding of the problems involved in our common undertaking, thus becoming better prepared to seek the cooperation of others, and that many will desire to contribute financially to support the work of the Society.

I feel very clearly the wisdom of the principle laid down by President Coble when he said, "It is clearly understood that in dealing with the universities Professor Ingraham will deal through the mathematics departments of the universities and will be guided in his work by their advice and wishes. In some localities it may be the judgment of the local members that Professor Ingraham should directly present the needs of the Society to the administrative officers of the university; in others they may prefer that he aid the local group by furnishing information and advice without his having direct contact with anyone outside the department of mathematics." From many of the places which I have already arranged to visit I have been informed that it will be expedient for me to see the president, deans, or other administrative officers involved, but this, of course, in no way needs to be considered a precedent to be followed generally, when the judgment of the local group may be otherwise. It is my hope that in each place that I visit I may have the opportunity to discuss the work of the Society with as large a group of mathematicians as possible. It might be well for me to have a chance to speak to the group as a whole and also to any individuals who wish to ask questions concerning contributing membership, gifts to the Society, or modes of obtaining cooperation.

I think it should be clear that in a few places it would be unjust to expect either the members or the institution to do anything at present, but an understanding, at this time, of the problems might lead to further cooperation when financial conditions improve. The officers of the Society feel it would be desirable if in the future those who reach a certain degree of advancement and security in the mathematical profession should as a matter of course become contributing members.

It has been impossible for me as yet to complete my itinera:y, since some very important work must be completed next fali before definite appointments for the rest of the year can be made. A rough schedule is as follows: 
Late September and October New England

Early November

Eastern Canada

November and December and early January Middle West

Late January and early February

\section{South}

Late February and March

Middle Atlantic states

Late April and May

Mountain states and Pacific coast

I shall strive by correspondence to be in touch with many mathematical groups which because of the limitations of time it will be impossible to visit. Since I shall visit only about seventy institutions of learning and since it will be impossible for me to see more than about half of the members of the Society, it is clear that the Society can carry out this program only through an adequate response to many appeals that of necessity must be written rather than verbal and general rather than personal.

I shall keep my headquarters at the University of Wisconsin where Miss Evelyn Hull will be in charge of my correspondence and of much of the detailed work connected with this plan. Many letters which I shall write will be typed in Madison and must necessarily be mailed without my signature.

The success of this whole plan does not depend upon the efforts of any one person or small group of individuals but upon the degree to which the mathematicians of America feel that the goal is essential and cooperate to attain it.

M. H. Ingraham, Associate Secretary

July 17,1934 